\title{
Isothermal Air Flow Investigation in Industrial Baking Oven of Different Impeller Locations using Computational Fluid Dynamics (CFD) Approach
}

\author{
Olawale Saheed Ismail ${ }^{1}$, Adetokunbo Andrew Awonusi ${ }^{1 *}$ and Rahman Akinoso ${ }^{2}$ \\ ${ }^{1}$ Department of Mechanical Engineering, University of Ibadan, \\ Oyo State, Nigeria \\ ${ }^{2}$ Department of Food Technology, University of Ibadan, Oyo State, Nigeria \\ ${ }^{*}$ Corresponding author: awonusitokunbo1@gmail.com
}

Published online:15 December 2021

To cite this article: Olawale Saheed Ismail, Adetokunbo Andrew Awonusi and Rahman Akinoso (2021). Isothermal air flow investigation in industrial baking oven of different impeller locations using computational fluid dynamics (CFD) approach. Journal of Engineering Science, 17(2), 73-91, https://doi.org/10.21315/jes2021.17.2.5.

To link this article: https://doi.org/10.21315/jes2021.17.2.5

\begin{abstract}
Computational fluid dynamics (CFD) modelling was performed on a forced convection oven to investigate the isothermal airflow. Three oven design configurations based on their impeller location (back, side, and top wall) were compared with respect to their Turbulence Kinetic Energy (TKE) profile to determine the optimal configuration design for quick uniform baking. The air velocity was estimated from both experimental and modelling approaches at specific points in an oven with the back walled impeller. The CFD model was validated resulting in a calculation error of $30.34 \%$ of actual velocity which was mainly due to limitation in grid density and the turbulence modelling. The other two oven configurations were simulated and their average TKE data were extracted and compared. The third configuration (impeller at the top wall) was found to have the highest average TKE of $3.55 \mathrm{~m}^{2} / \mathrm{s}^{2}$ followed by the first configuration (impeller at the back wall) with $3.30 \mathrm{~m}^{2} / \mathrm{s}^{2}$ which provides a relatively uniform TKE distribution across the cavity. The findings show the significance of impeller placement in oven performance.
\end{abstract}

Keywords: CFD, turbulence kinetic energy, impeller, oven, modelling

\section{INTRODUCTION}

In the baking industry, uniform heat distribution influenced by airflow is essential in reducing baking time. In an oven, optimum heat distribution is needed to produce a good quality baking product, which is dependent on parameters like convective type, heat source, air temperature, air motion, etc. The production of a highquality product is dependent on the oven operation and design (or configuration). 
Temperature and airflow velocity are very useful parameters in achieving product quality. ${ }^{1,2}$ Optimum temperature distribution and air velocity profile are dictated by the oven configuration and design. In designing an oven, baking time and energy efficiency should be considered.

To design the desired oven, experimental trial by error approach ${ }^{3}$ are performed on oven prototype to analyse its capabilities. This approach can be expensive. But computational fluid dynamics (CFD) provides an inexpensive approach whereby conservative equations, heat, and mass balance equations can be used to model the complex relationship and interaction in a system (oven) by discretising the system into smaller meshes and solving these equations at every node to show a parameter profile or distribution.

CFD has been used often to investigate the essence of improvement on food processing devices. It has been used extensively to study volume expansion on the product, species behaviour in the product, temperature and velocity distribution in the study domain, heat transfer activities, etc. Examples are simulations that involve the sterilisation of food through heating, ${ }^{4}$ study on the simulation of food dehydration machines, ${ }^{5}$ analyses on the simulation of refrigerated compartments, ${ }^{6}$ and simulations to study and analyse the ripening process of fermented food.?

Studies have been carried out using CFD simulation to model baking processes. Therdthai et al. ${ }^{8}$ created a two-dimensional CFD simulation of an industrial continuous baking process using a steady state assumption under nine oven operation condition so as to provide information on the temperature distribution and airflow pattern around a dough. Therdthai et al. ${ }^{9}$ went further using transient state assumption, employing it on a moving grid and applying it on a 3D CFD model to predict the temperature distribution in and around the dough.

CFD provides a route to create an oven model of possible designs and configurations to study its capability and ways in designing an oven of the desired optimum baking process before the prototype is created. In addition, CFD can help in reconfiguring an existing oven in its energy efficiency and also optimising its baking process. Since this study involves the CFD simulation of an industrial baking oven, it centred on these major areas.

Mirade et al. ${ }^{10}$ developed 3D CFD models to study the velocity and temperature profile of air inside an industrial gas-fired oven used in baking biscuits. From the models, he discussed the complex circulation of airflow from the inlet and the outlet at the oven ends and of extraction of air at different extraction points along the oven length. Khoddam ${ }^{11}$ developed a 2D CFD model to analyse better 
ways to save energy in an oven by studying the hot air distribution in the oven chamber and the result on some oven parameters. From his result, it was stated that to achieve better temperature distribution, oven design is essentially based on its configuration. The results gotten can be used to improve the existing oven for issues on energy saving.

Smolka et al. ${ }^{12}$ presented an experimental analysis to validate the spatial and temperature field of a 3D CFD model of a laboratory oven chamber. The outcomes depict an agreement between the experiment and the CFD modelled temperature and velocity values. The study provides possible changes in the construction of a system that can improve uniformity in temperature in an oven. Suvanjumrat and Loksupapaiboon ${ }^{13}$ applied CFD to model and investigate the hotair stream through the grille of the branch hot-air channels inside the transport stove. OpenFOAM CFD programming was utilised to play out the computational strategy to recreate the complex hot-wind current. The hot-air branch pipes were controlled to improve uniformity of the temperature distribution regarding the simulated results. The temperature examination of comparing the experiment and simulated data at each data point along the oven length shows that the CFD model affirmed a viable improvement and accuracy of a calculation error of less than $8.99 \%$.

Laocharoenpongsang et al. ${ }^{14}$ examined the flow conduct of hot air inside a conceptual design oven in which the blower operates at speed of $1155 \mathrm{rpm}$ to instigate desired air circulation. Tray plate placement affected the flow field from the CFD results and diminished flow velocity in the space between the plates. With plates placed, pressure drop was additionally higher when contrasted with that of the oven without the plate. Palacio-Caro et al..$^{15}$ investigated numerically the changes in the thermal efficiency of the electric heater furnace due to changes in the rotating speed of the fan and the effects on the homogeneity of the temperature and the rate of heat transfer to the load. Heat losses through the walls were calculated based on the external temperature measurement of the furnace. Through CFD, four distinct speeds were simulated, temperature uniformity was improved at increased rotational speeds due to fan creating recirculation zone which enhances heat transfer and flow mixing but thermal efficiency reduces. Therefore, the ovenquality ought to be adjusted to acquire a gain while controlling the rotational speed.

Garg et al. ${ }^{16}$ presented a study using particle-imaging velocimetry (PIV) application to examine the airflow in a convection oven with a bread sample placed at three distinct points on a baking plate. The cavity of the oven was adjusted for optical access, and airflow was estimated at room temperature. A $30 \mathrm{~mW}$ green laser was utilised for reviewing the tracer particles in a laser sheet that was created 
utilising incense sticks. The flow profile was caught using a camera of $1000 \mathrm{fps}$ speed. The turbulent kinetic energy and vorticity data gotten from velocity fields reflected sufficient air mixing inside the oven cavity. The boundary layer flow derived data created in this investigation can be utilised for the refined portrayal of complex air or gas flow in a closed convection oven cavity.

Recent literature search has rendered no findings of simulations being used to study the effect of oven configuration on oven quality. Therefore, the objectives of this work are to determine the best oven design or configuration that will provide airflow distribution for a quick baking process. For this goal, a validated model was applied to three different oven configurations to obtain simulated turbulence kinetic energy (TKE) data for each configuration, from which the design with the highest TKE should be the oven design with the shortest time for baking products.

\section{MATERIALS AND METHODS}

\subsection{Oven Description}

The oven used for the modelling was the oven implemented in the study by Piaia et al. ${ }^{17}$ It is an industrial batch forced convection oven, as shown in Figure 1a which has an external dimension of $98 \mathrm{~cm}$ width, $130 \mathrm{~cm}$ high, and $100 \mathrm{~cm}$ depth. The oven cavity dimension is measured at $70 \mathrm{~cm}$ width, $90 \mathrm{~cm}$ in height, and $84 \mathrm{~cm}$ depth, and contains 8 grid shelves, each measured at $59 \mathrm{~cm}$ width and $65 \mathrm{~cm}$ depth. The heaters are strings of coils present in a tube of $2 \mathrm{~cm}$ diameter and $75 \mathrm{~cm}$ long placed serial along two opposite walls of the cavity.

A radial fan (impeller) of $35 \mathrm{~cm}$ diameter is attached at the back wall of the oven with the sole purpose of providing forced convection into the oven cavity. It operates by sucking in air axially from the cavity and pushing the air radially, in a centrifugal manner, back into the cavity. The air passes through the series of heater tubes placed vertically at both sides of the cavity thereby heating the air and then flows throughout the cavity. The impeller, in Figure $1 \mathrm{~b}$, is a single suction open impeller of 12 blades with a radial design that rotates in an anti-clockwise manner with a maximum speed of $362.85 \mathrm{rad} / \mathrm{sec}$. For this study, a rotational speed of $181.17 \mathrm{rad} / \mathrm{sec}$ was used for the simulation and validation. ${ }^{17}$ 


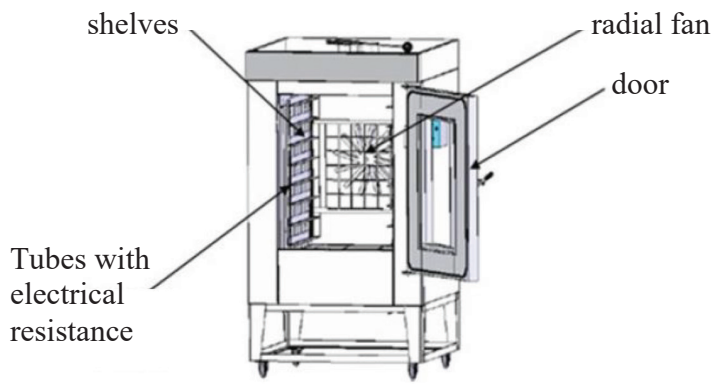

(a)

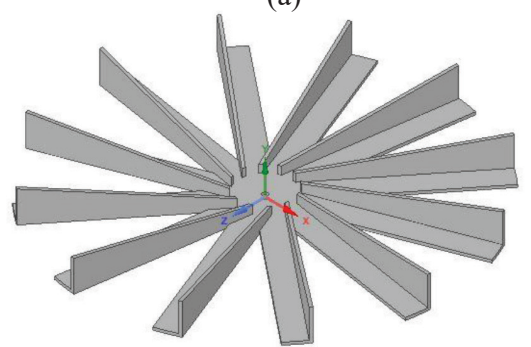

(b)

Figure 1: Forced convection oven: (a) oven illustration ${ }^{17}$ and (b) impeller.

\subsection{Oven Designs/Configurations}

For this study, three design geometries were used as shown in Figure 2, having the same dimension as described in Section 2.1. What makes these designs different from each other is the location or position of their impeller. The first design is labelled "Design 1" modelled after the actual oven which has its impeller at the back, while the second design (impeller located at the sidewall) is labelled "Design 2" and the third, "Design 3" (impeller at the top wall). In these designs, the heaters, shelf railings, and impeller enclosed in the oven cavity were depicted. 


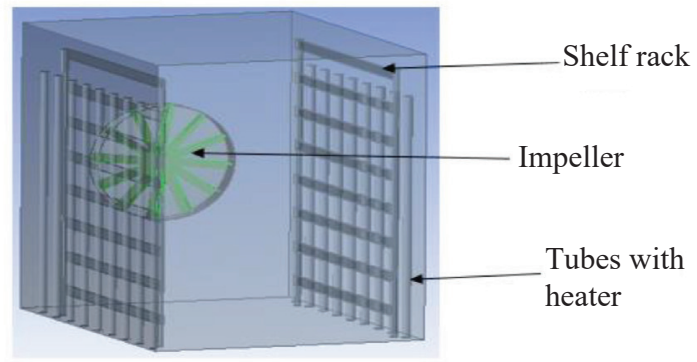

(a)

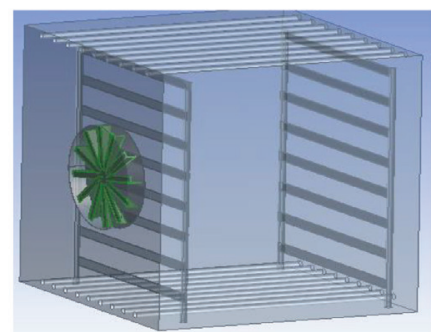

(b)

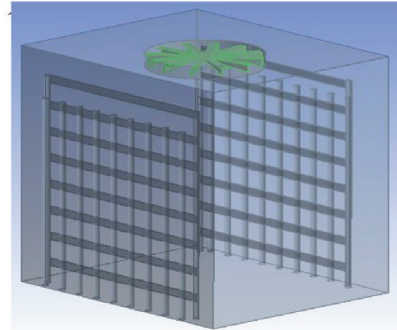

(c)

Figure 2: Oven configuration: (a) Design 1, (b) Design 2, and (c) Design 3

\subsection{Governing Equations}

The continuity and momentum equations, which describe the mass and the momentum respectively, of a moving fluid as air, can be written mathematically for a 3-dimensional continuum flow isothermal process at steady state as follows in differential form: ${ }^{18}$

Continuity equation:

$$
\frac{\partial \rho_{a} \boldsymbol{u}_{j}}{\partial \boldsymbol{x}_{j}}=0
$$

Navier-Stokes equation:

$$
\begin{aligned}
& \frac{\partial \rho_{a} \boldsymbol{u}_{j} \boldsymbol{u}_{i}}{\partial \boldsymbol{x}_{j}}=\frac{\partial}{\partial x} \mu_{a}\left(\frac{\partial \boldsymbol{u}_{i}}{\partial \boldsymbol{x}_{j}}+\frac{\partial \boldsymbol{u}_{j}}{\partial \boldsymbol{x}_{i}}\right)-\frac{\partial}{\partial \boldsymbol{x}_{i}}\left(p+\frac{2}{3} \mu_{a} \frac{\partial \boldsymbol{u}_{j}}{\partial \boldsymbol{x}_{j}}\right) \\
& +\left(\rho_{a}-\rho_{0}\right) \boldsymbol{g}_{i}+\boldsymbol{f}_{i}
\end{aligned}
$$


The variables $u_{i}$ are the Cartesian components of the mean velocity vector $\boldsymbol{u}(\mathrm{m} / \mathrm{s}), \rho(\mathrm{Pa})$ is the pressure, $\mathrm{g}_{i}$ the $i$ th component of the gravity vector, and the term $\mathrm{f}_{i}(\mathrm{~kg} / \mathrm{cm} 3)$ represents the inner volumetric mass generation rate. The air properties involved are the density $\rho_{a}\left(\mathrm{~kg} / \mathrm{m}^{3}\right)$, and the viscosity $\mu_{\mathrm{a}}(\mathrm{kg} / \mathrm{m} \mathrm{s}) .{ }^{18}$

The standard K-Epsilon turbulence developed by Jones and Launder ${ }^{19}$ was implemented in the physical model. It was preferred to that of realisable $\mathrm{K}$-Epsilon model ${ }^{20}$ because stationary and rotational domains are involved in the computational domain which causes realizable k-Epsilon to produce non-physical turbulent viscosity. ${ }^{21}$

TKE equation:

$$
\frac{\partial}{\partial \boldsymbol{x}_{i}}\left(\rho k \boldsymbol{u}_{i}\right)=\frac{\partial}{\partial \boldsymbol{x}_{i}}\left[\left(\mu+\frac{\mu_{t}}{\sigma_{k}}\right) \frac{\partial k}{\partial x_{j}}\right]+G_{k}+G_{b}-\rho \varepsilon^{-} Y_{M}+S_{k}
$$

Dissipation rate equation:

$$
\frac{\partial}{\partial \boldsymbol{x}_{i}}\left(\rho \varepsilon \boldsymbol{u}_{i}\right)=\frac{\partial}{\partial \boldsymbol{x}_{j}}\left[\left(\mu+\frac{\mu_{t}}{\sigma_{\varepsilon}}\right) \frac{\partial \varepsilon}{\partial \boldsymbol{x}_{j}}\right]+C_{1 \varepsilon} \frac{\varepsilon}{k}\left(G_{k}+C_{3 \varepsilon}\left(C_{b}\right)-C_{2 \varepsilon} \frac{\varepsilon^{2}}{k}+S_{\varepsilon}\right.
$$

Where $\mu_{t}=\rho C_{\mu} \frac{k^{2}}{\mathcal{E}}$

In equations (3) and (4), $G_{b}$ represents the TKE generation as a result of buoyancy, $G_{k}$ is the TKE generation as a result of the velocity gradients mean, incompressible turbulence, $Y_{M}$ is the fluctuating dilatation contribution to the total dissipation rate, while $\mu_{t}$ is the turbulent viscosity. $S_{k}$ and $S_{\varepsilon}$ are source terms defined by the user. ${ }^{21} \sigma_{k}$ and $\sigma_{\varepsilon}$ are the turbulent Prandtl numbers for $k$ and $\varepsilon . C_{l \varepsilon}$, $C_{2 \varepsilon}, C_{\mu}$ and $C_{3 \varepsilon}$ are constants.

$$
\sigma_{k}=1.0, \sigma_{\varepsilon}=1.3, C_{1 \varepsilon}=1.44, C_{2 \varepsilon}=1.92, C_{\mu}=0.09 .{ }^{19}
$$

\subsection{CFD Simulation}

The discretisation and solution of of Eq. 1 to Eq. 4 was performed by ANSYS Fluent. It is a solver which uses FVM (Finite Volume Method) to solve the physical model in section 2.3. The models were run on an Intel Core $15-43002.5 \mathrm{GHz}$ processor and 8GB RAM computation system. 


\subsubsection{Design 1}

A three-dimension design of the oven cavity (Figure 1a) was recreated. The cavity walls, heater, and impeller were depicted by tetrahedral meshes in the computational grid with maximum skewness and minimum orthogonal quality of 0.85 and 0.15 , respectively. As shown in Figure 3, the model was set up to the following assumption and boundary conditions: steady-state, turbulence, and isothermal flow. The no-slip condition was defined on all the walls to depict a closed domain. The stationary and rotational cell zones were set up as air. The impeller was subtracted from the rotational cell zone to form a dent. The railing and heaters were also subtracted from the stationary zone. The frame motion of $-1730 \mathrm{rpm}$ in rotational speed was set to the rotational cell zone. Properties of air are assumed as constants and calculated at a reference temperature value of 25 .

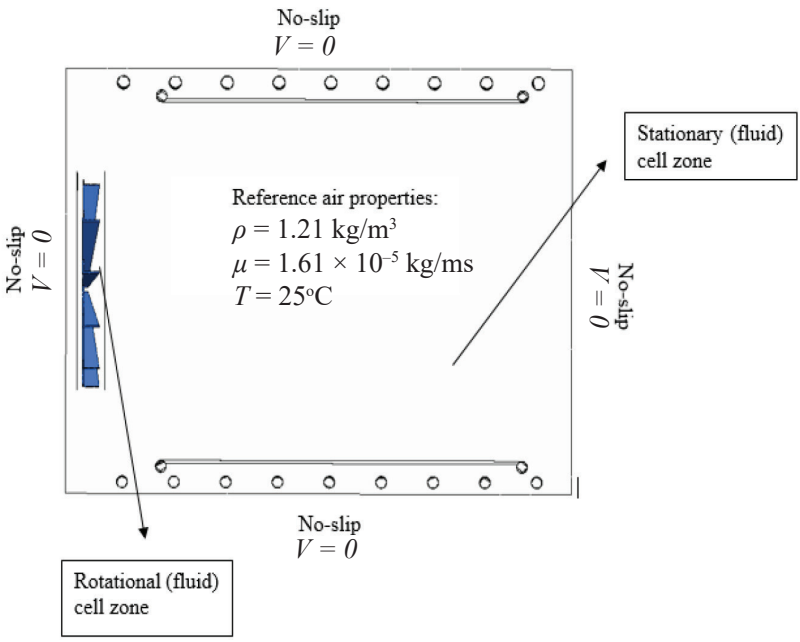

Figure 3: Setup schematic of the model's boundary condition (cross-sectional plan view).

Three different mesh sizes were tested for their quality: a coarse mesh of $20 \mathrm{~mm}$ element size, an intermediate mesh of $13.28 \mathrm{~mm}$ element size, and a finer mesh of $8 \mathrm{~mm}$ element size. A local body sizing of $6.5 \mathrm{~mm}$ was applied to the rotational cell zone of the three mesh sizes stated above.

The second-order upwind ${ }^{22}$ was used as the discretisation scheme for the momentum conservation and transport equation. The algorithm for pressurevelocity coupling called SIMPLE was used to solve the discretised equation iteratively and the solution convergence was assumed to occur when the addition of absolute continuity equation residuals fell below $10^{-4}$. Then velocity and TKE 
data were extracted from the result, where the simulated velocity data was used for validation and that of TKE used for the analysis of the oven performance.

\subsubsection{Design 2 and Design 3}

After validation from which the model (Design 1) has proven to be accurate to some extent. The other two designs (Design 2 and Design 3) were passed through similar mesh, assumption, boundary conditions, and setup procedure as undergone by Design 1 and then simulated. When convergence has occurred, their TKE data only were extracted from their simulated results and then used for oven performance analysis and compared with that of Design 1.

\subsection{Experimental Method}

Experimental data were extracted from the study of Piaia et al. ${ }^{17}$ The velocity values were obtained based on the relationship between the local fluid velocity and the heat flux from the heated sensing element which is placed in a flow. The rate of heat exchange between the filament and the environment is a function of speed. The experimental data were estimated using a hot-film anemometer. ${ }^{17}$ Velocity readings were taken at 48 distinct locations in the oven cavity. Figure 4 displays the velocity measurement locations in the cavity illustrating 12 data locations on four planes (shelves) each.

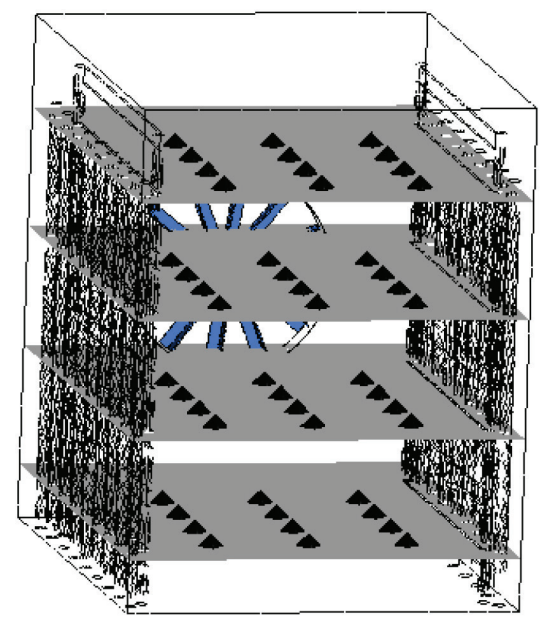

Figure 4: Experimental velocity measurement locations. 
The CFD modelling error was calculated using the equation (5) from Piaia et al. ${ }^{17}$ which is the percentual absolute rate between the experimental and CFD calculated velocity magnitude.

$$
p=\frac{100}{n} \cdot \sum \frac{\left|v_{C F D}-v_{\exp }\right|}{v_{\exp }}
$$

where $v_{\text {exp }}$ is the experimental velocity in the total time of $120 \mathrm{~s}, v_{C F D}$ is the calculated value of the simulated model, and $n$ is the number of the experimental data.

\section{RESULTS AND DISCUSSION}

Owing to the complex geometry of the impeller and its swirl, the air does not move in a straight-forward direction through the oven cavity toward the impeller, but it blows out radially toward the cavity wall across the tubes at the wall, and then flows into the cavity space (where the food products are, for baking to occur) from all directions as it is being sucked back to the centre of the impeller. These are illustrated in Figure 5, which shows the velocity vectors in a horizontal and vertical cross-section of the model.

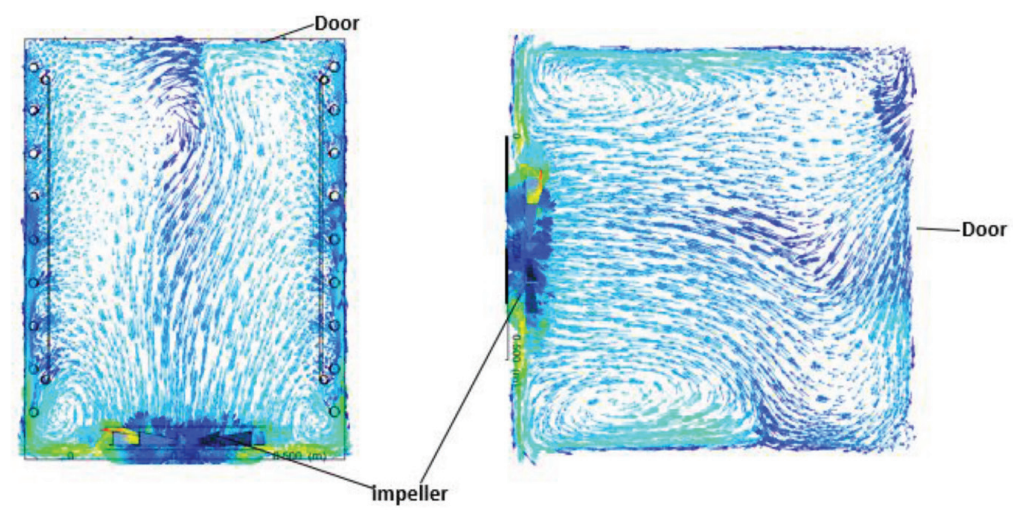

Figure 5: Horizontal and vertical cross-section of the simulated velocity vector.

Table 1 shows the mean errors $(p)$ and the computational effort and durations acquired by the CFD model with the three mesh sizes when compared to the measurements. The error reduces as the mesh refinement increases at the expense of increasing the computational time and effort. Due to the constraint of the accessible computer resources and ability, mesh refinement was limited. 
Table 1. Grid dependence test and computational time.

\begin{tabular}{lllc}
\hline Element size (mm) & Number of elements & $\bar{p}(\%)$ & Simulation time (min) \\
\hline 20.00 & 443,092 & 64.98 & 194 \\
13.28 & $1,204,979$ & 46.88 & 325 \\
8.00 & $2,946,113$ & 30.34 & 668 \\
\hline
\end{tabular}

Consequently, some errors were produced as a result of simplifying the oven geometry and its components such as the impeller and shelf placements. When the CFD model (for Design 1) simulated mean velocities were analysed, an error of $30.34 \%$ was obtained when utilising the finer mesh of $8 \mathrm{~mm}$ element sizing.

\subsection{Model Validation}

A comparative analysis of the measured and the calculated velocity magnitude on shelves 2, 4, 6, and 8 were conducted and were presented in Figures 6-9, respectively. A comparative plot was made between the calculated and measured velocity magnitudes on different horizontal lines along the y-coordinate direction (with respect from the distance to the impeller) for the right side, centre, and left side on shelves $2,4,6$, and 8 of the oven cavity.

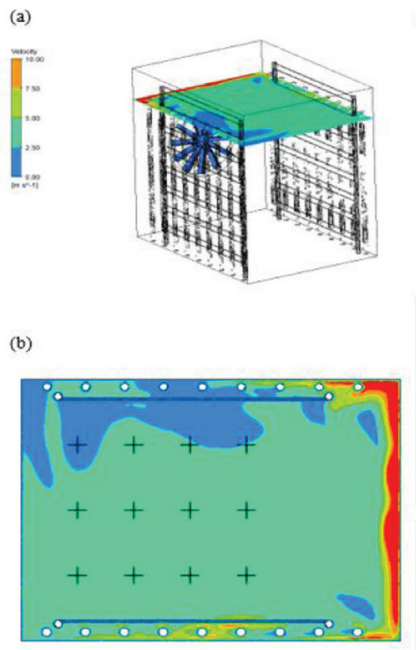

(c)

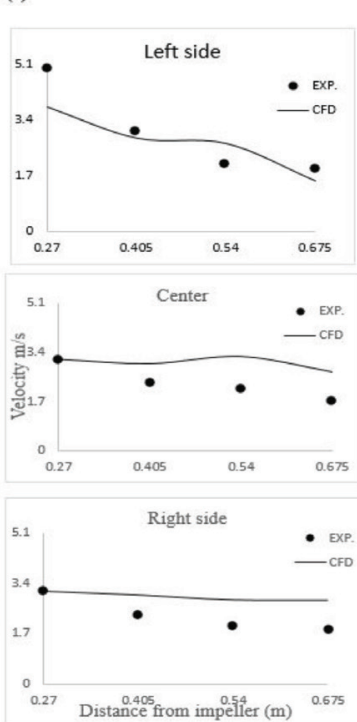

Figure 6: Air-flow profile, Shelf 2: (a) horizontal cross-section, (b) location of data point, and (c) comparative plot of measured velocity magnitude and that of simulation. 


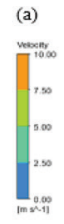

(c)
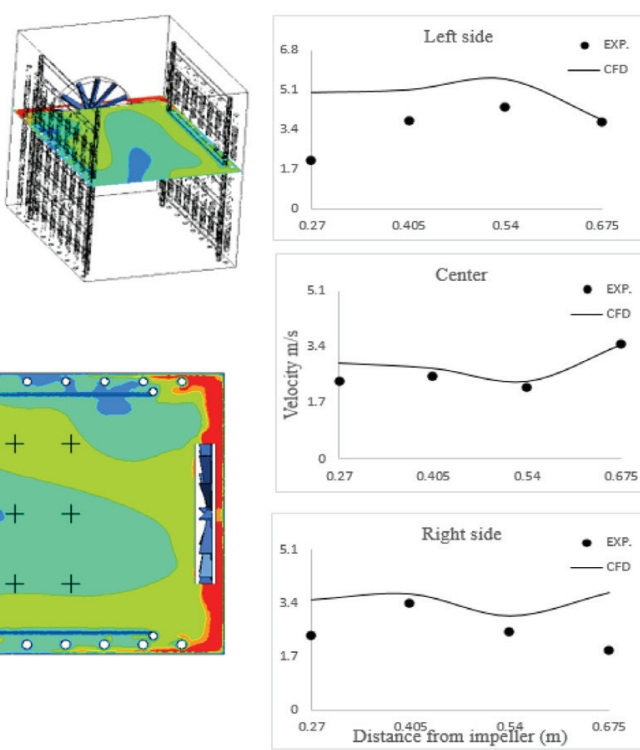

Figure 7: Air-flow profile, Shelf 4: (a) horizontal cross-section, (b) location of data point, and (c) comparative plot of measured velocity magnitude and that of simulation.

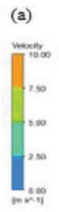

(c)
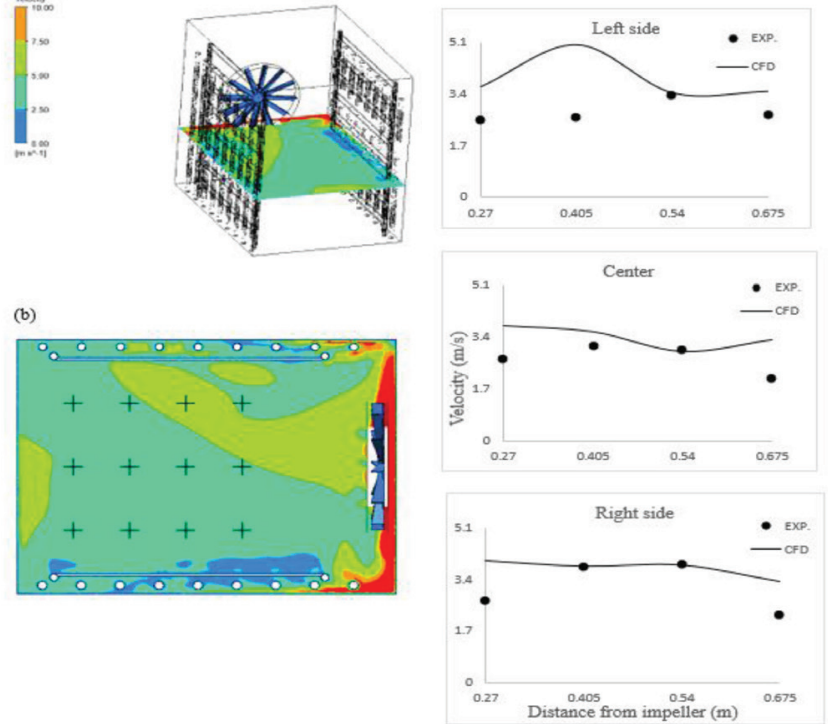

Figure 8: Air flow profile, Shelf 6: (a) horizontal cross-section, (b) location of data point, and (c) comparative plot of measured velocity magnitude and that of simulation. 
(a)

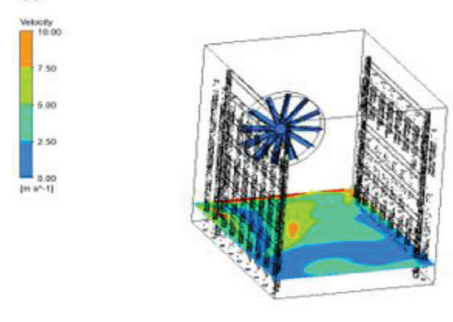

(b)

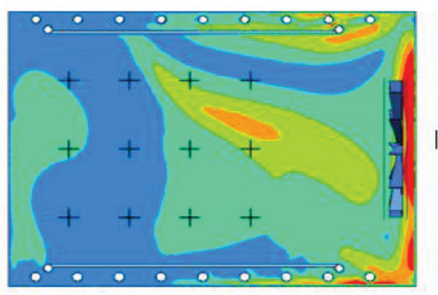

(c)

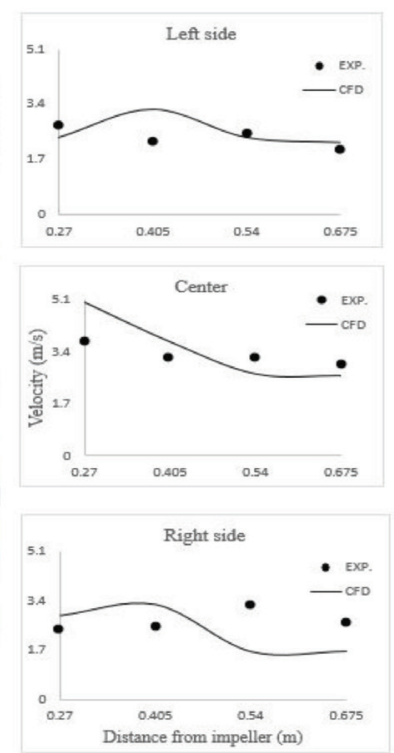

Figure 9: Air flow profile, Shelf 8: (a) horizontal cross-section, (b) location of data point, and (c) comparative plot of measured velocity magnitude and that of simulation.

Figures $6 \mathrm{~b}, 7 \mathrm{~b}, 8 \mathrm{~b}$ and $9 \mathrm{~b}$ show the data point locations which are positioned to record/collect velocity data as airflow further away from the impeller. From these figures, the upper locations represent the right side of the shelves, the middle ones represent the centre while the lower ones represent the left side. The CFD model captures the trend of the airflow velocity in most of the available shelves as shown in Figures 6c, 7c, 8c, and 9c.

As expected, there are higher velocities at the vicinity of the impeller as compared to other regions and zero velocity at the wall, door, and components of the oven due to the no-slip condition. Table 2 depicts the error distribution of the model at the four shelves. There are higher modelling errors in Shelves 4 and 6 as compared to the others. This may be due to the model's inability to predict correct velocity at the region of higher turbulence flow towards the impeller, but shelves further from the impeller have reduced errors. 
Table 2: Calculation error distribution over the four different shelves.

\begin{tabular}{llll}
\hline Shelf & $\bar{v}_{\text {exp }}(\mathrm{m} / \mathrm{s})$ & $\bar{v}_{C F D}(\mathrm{~m} / \mathrm{s})$ & $p(\%)$ \\
\hline 2 & 2.56 & 2.90 & 28.93 \\
4 & 2.88 & 3.75 & 36.05 \\
6 & 2.99 & 3.69 & 32.51 \\
8 & 2.72 & 2.82 & 23.87 \\
\hline
\end{tabular}

An average of $30.34 \%$ of the measured velocity was estimated as the CFD calculation error. As explained above, it could be caused by some limitations in the density of the grid (high skewness value), simplicity of the oven geometry, and the turbulence modelling. It should also be noted that the error magnitude falls in line with some literature reported on CFD studies, such as Piaia et al. ${ }^{17}$ which accounted for $18.14 \%$ average relative error from modelling airflow in a forced convection oven. Therdthai et al. ${ }^{9}$ obtained $37.31 \%$ average error modelling and comparing CFD result with actual velocity in an industrial continuous baking process. Mirade and Daudin ${ }^{23}$ observed a $40 \%$ error to estimate an air velocity profile in a chiller containing objects.

\subsection{Oven Design Performance}

The turbulence model used in the modelling of airflow in design 1 was implemented in Design 2 and Design 3, since it has been validated and shown to some extent to have a good agreement with the measured data.

One of the criteria for better performance of an oven is its ability to transfer heat to the product (i.e. heat transfer) in its cavity for better and quick baking. Vlahostergios et al. ${ }^{24}$ observed that increase in turbulence intensity enhances heat transfer. Turbulence intensity is directly proportional to turbulence kinetic energy. Therefore, the simulated TKE profile was used as a substitute to highlight heat transfer profile in the oven designs. 
(a)

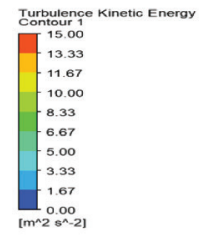

(b)

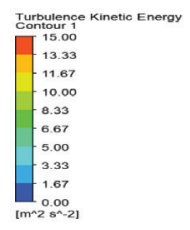

(c)

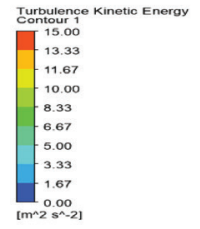

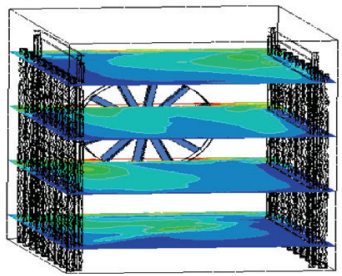
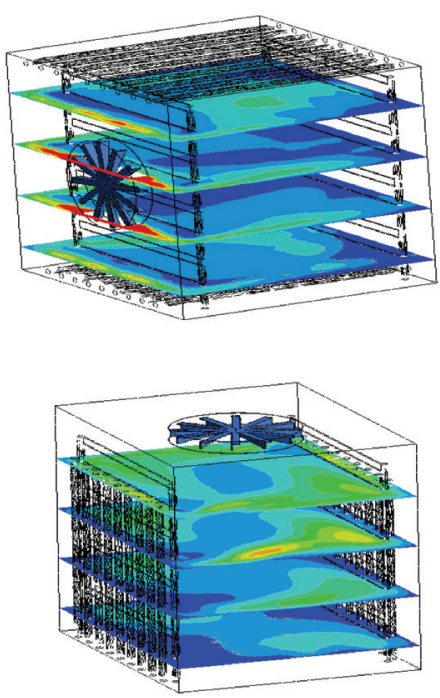

Figure 10: The TKE profile: (a) Design 1, (b) Design 2, and (c) Design 3

The TKE of the 3 designs was calculated by the CFD simulation as explained in Section 2.4. The simulated TKE findings for the oven designs were extracted and shown in Figure 10. The average TKE was calculated and a comparative chart was used to analyse them as shown in Figure 11. Design 3 has the highest average TKE of $3.55 \mathrm{~m}^{2} / \mathrm{s}^{2}$ followed by Design 1 with $3.30 \mathrm{~m}^{2} / \mathrm{s}^{2}$. The average TKE is higher in the top shelves 2 and 4 in Design 3 as compared to the other designs but drops drastically in the bottom shelves 6 and 8. This is as a result of the air flowing radially from the impeller outlet at higher TKE but losing energy as it goes down the cavity and is being suck back to the top through all the four shelves centre at constant lower TKE to the impeller inlet. Products (i.e. dough) placed at the centre of all the shelves in Design 3 may experience lesser heat transfer (low TKE) as compared to the surrounding products. 


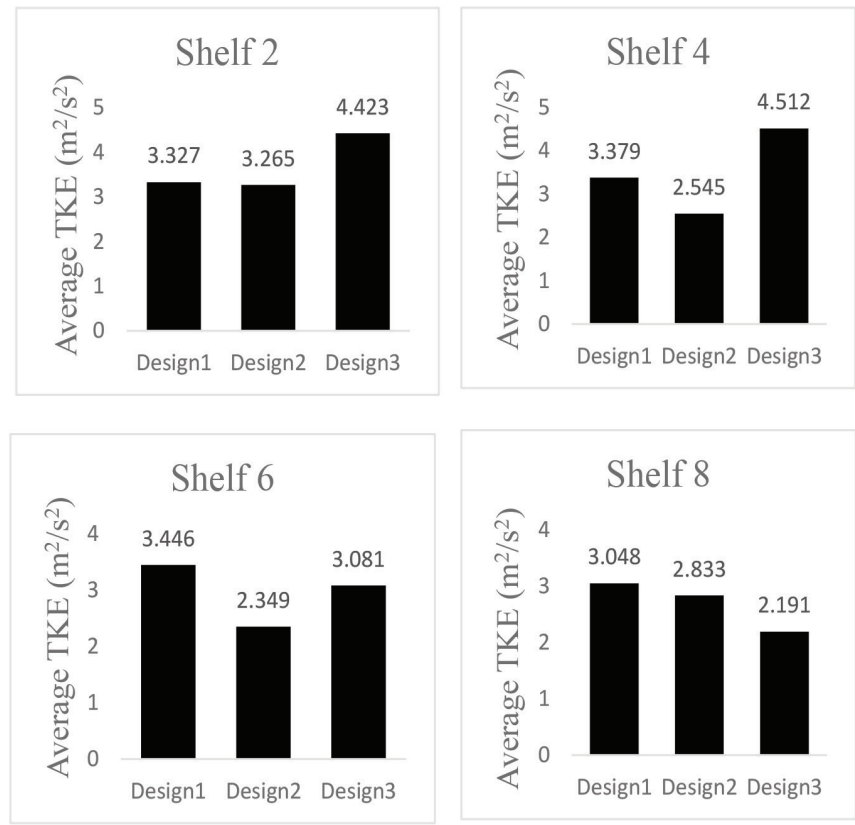

Figure 11: Comparative chart of TKE on each shelf in different designs.

In Design 1, it was observed that there is a presence of relatively uniform TKE across the cavity as compared to the other designs, which is ideal for batch baking where all shelves are being utilised. Here, the airflow loses its TKE as it approaches the cavity door, and the path taken by the air when being sucked back to the impeller inlet is channelled across the space between two middle shelves as opposed to Design 3 where the paths are channelled through the centre of all shelves.

\section{CONCLUSION}

A three-dimensional CFD modelling of a forced convection oven was developed to simulate the flow dynamics of air. The isothermal airflow at a steady state obtained by the CFD modelling technique shows a good approximation in its flow pattern when compared to that of the experimental measurement. The average error remains $30.34 \%$ of the actual velocity due to limitations in turbulence modelling, grid density, assumption, and simplification of some of the oven geometry features.

From this study, three oven designs with different impeller positions were developed, and they were modelled to simulate and analyse their respective TKE profiles. Design 3 (the oven with its impeller at the top wall) was observed to have 
the highest average TKE of $3.55 \mathrm{~m}^{2} / \mathrm{s}^{2}$ than the others which depicted that Design 3 will experience quick baking time as compared to the others but Design 1 (the oven with its impeller at the back wall) is best suited for uniform baking where all shelves are being made use of while Design 2 exhibits the lowest average TKE and are less uniform.

\section{REFERENCES}

1. Velthuis, H., Dalhuijsen, A. \& de Vries, U. (1993). Baking ovens and product. London: Sterling Publication Limited.

2. Carvalho, M. G. \& Nogueira, M. (1997). Improvement of energy efficiency in glass making furnace, cement kilns, and baking oven. Appl. Therm. Eng., 17(8-10), 921-933, http://doi.org/10.1016/S1359-4311(97)00001-X.

3. Therdthai, N., Wuttijumnong, P. \& Netipunya, S. (2008). Computational Fluid Dynamics Simulation of Temperature Profiles during Batch Baking. Kasetsart J. (Nat. Sci.), 42, 175-181.

4. Ghani, A. \& Farid, M. M. (2007). Thermal sterilization of food using CFD. In D. W. Sun (Ed.). Computational Fluid Dynamics in Food Processing. New York: CRC Press, 331-345.

5. Mirade, P. (2007). Prediction of the air velocity field in modern meat dryers using unsteady CFD model. In D. W. Sun (Ed.). Computational Fluid Dynamics in Food Processing. New York: CRC Press, 223-246.

6. Cortella, G. (2007). CFD Aided Retail Cabinets Design. In D. W. Sun (Ed.). Computational Fluid Dynamics in Food Processing. New York: CRC Press, 84-99.

7. Mirade, P. (2008). Computational fluid dynamics (CFD) modelling applied to the ripening of fermented food products: Basics and advances. Trends Food Sci. Technol., 19(9), 472-481, http://doi.org/10.1016/j. tifs.2008.01.014.

8. Therdthai, N., Zhou, W. \& Adamczak, T. (2003). Two-dimension CFD modeling and simulation of an industrial continuous bread baking oven. $J$. Food Eng., 60(2), 211-217, http://doi.org/10.1016/S0260-8774(03)000438.

9. Therdthai, N., Zhou, W. \& Adamczak, T. (2004). Simulation of starch gelatinization during baking in a traveling-tray oven by integrating a three-dimensional CFD model with kinetic model. J. Food Eng., 65(4), 543-550, https://doi.org/10.1016/j.jfoodeng.2004.02.018. 
10. Mirade, P., Daudin, D., Ducept, F., Trystram, G. \& Clement, J. (2004). Characterization and CFD modelling of air temperature and velocity profiles in an industrial biscuit baking tunnel oven," Food Res. Int., 37(10), 1031-1039, http://doi.org/10.1016/j.foodres.2004.07.001.

11. Khoddam, S. (2013). CFD application on food industry; Energy saving on the bread oven. Middle-East J. Sci. Res., 13(8), 1095-1100.

12. Smolka, J., Bulinski, Z. \& Nowak, A. J. (2013). The experimental validation of a CFD model for a heating oven with natural air circulation. Appl. Therm. Eng., 54(2), 387-398, http://doi.org/10.1016/j. applthermaleng.2013.02.014.

13. Suvanjumrat, C. \& Loksupapaiboon, K. (2020). Improvement of thermal distribution in the rubber-glove former conveyor oven by OpenFOAM. Eng. J., 24(2) 109-120, http://doi.org/10.4186/ej.2020.24.2.109.

14. Laocharoenpongsang, S., Jiamrittiwong, P., Pana-Suppamassadu, K. \& Srisurat, T. (2018). Study of air circulation inside the oven by computational fluid dynamics: Designing tomorrow towards sustainable engineering and technology, presented at the 8th International TIChE Conference (ITIChE 2018), A-ONE The Royal Cruise Hotel Pattaya, Thailand.

15. Palacio-Caro, I. D., Alvarado-Torres, P. N. \& Cardona-Sepúlveda, L. F. (2020). Numerical simulation of the flow and heat transfer in an electric steel tempering furnace. Energies, 13(14), 3655, http://doi.org/10.3390/ en13143655.

16. Garg, A., Shrivastava, C., Murai, Y. \& Windhab, E. J. (2019). Impact of airflow on the heat transfer conditions inside an oven cavity, characterized using particle imaging velocimetry. Phys. Fluids, 31(10), 107109, http:// doi.org/10.1063/1.5122800.

17. Piaia, J., Claumann, C., Quadri, M. \& Bolzan, A. (2018). Air flow CFD modeling in an industrial convection oven. In Driss, Z., Necib, B. \& Zhang H. C. (eds). CFD Techniques and Thermo-Mechanics Applications. Springer, Cham, 1-12, https://doi.org/10.1007/978-3-319-70945-1_1.

18. Verboven, P., Scheerlinck, N. \& De Baerdemaeker, J., \& Nicolai, B. (2000). Computational fluid dynamics modelling and validation of the isothermal airflow in a forced convection oven. J. Food Eng., 43(2), 61-73, http://doi.org/10.1016/S0260-8774(99)00133-8.

19. Jones, W. \& Launder, B. (1972). The prediction of laminarisation with a two-equation model of turbulence, Int. J. Heat Mass Transf., 15(2), 301-313, http://doi.org/10.1016/0017-9310(72)90076-2.

20. Shih, T., Liou, W., Shabbir, A., Yang, Z. \& Zhu, J. (1995). A new k- eddy viscosity model for high reynolds number turbulent flows. Comput. Fluids, 24(3), 227-238, http://doi.org/10.1016/0045-7930(94)00032-T. 
21. ANSYS Inc. (2009). Realizable $k$ - $\varepsilon$ model. Retrieved from https://www. afs.enea.it/project/neptunius/docs/fluent/html/th/node60.htm on 13 April 2019

22. Barth, T. \& Jespersen, D. (1989). The design and application of upwind schemes on unstructured meshes. Paper presented at the AIAA 27th Aerospace Sciences Meeting, Reno, Nevada, 9-12 January 1989, 1-12, https://doi.org/10.2514/6.1989-366.

23. Mirade, P. \& Daudin, J. (1998). Numerical simulation and validation of the air velocity field in a meat chiller. Internat. J Appl. Sci. Comput, 5(1), $11-24$.

24. Vlahostergios, Z., Missirlis, D., Flouros, M., Albanakis, C., \& Yakinthos, K. (2014). Effect of turbulence intensity on the pressure drop and heat transfer in a staggered tube bundle heat exchanger. Exp. Therm. Fluid Sci., 60, 75-82, http://doi.org/10.1016/j.expthermflusci.2014.08.011. 